http://dx.doi.org/10.32929/2446-8355.2020v29n1p1-10

v.29, n.1, p.1-10, 2020

\title{
DESEMPENHO PRODUTIVO DE GENÓTIPOS DE CANOLA NA REGIÃO CENTRAL DO RIO GRANDE DO SUL
}

\author{
Eduardo Leonel Bottega ${ }^{1 *}$; Zanandra Boff de Oliveira ${ }^{1}$; Alberto Eduardo Knies ${ }^{2}$; Clarissa \\ Moraes da Silva ${ }^{3}$; Irajá Jantsch de Souza ${ }^{3}$; Larrissa Ribeiro Rodrigues ${ }^{3}$; Tiago Tondolo Link ${ }^{3}$ \\ ${ }^{1}$ Docente do curso de Engenharia Agrícola, Universidade Federal de Santa Maria (UFSM), campus de Cachoeira \\ do Sul, Cachoeira do Sul/RS. *E-mail do autor correspondente: eduardo.bottega@ufsm.br \\ ${ }^{2}$ Docente do curso de Agronomia, Universidade Estadual do Rio Grande do Sul (UERGS), campus de Cachoeira \\ do Sul, Cachoeira do Sul/RS. \\ ${ }^{3}$ Graduando em Engenharia Agrícola, Universidade Federal de Santa Maria (UFSM), campus de Cachoeira do \\ Sul, Cachoeira do Sul/RS.
}

Recebido: 23/10/2018; Aceito: 26/11/2019

RESUMO: A canola apresenta-se como potencial cultura para exploração agrícola no Brasil, podendo ser inserida em sistema de rotação de culturas, contudo, a identificação de épocas de semeadura e do potencial produtivo dos genótipos disponíveis no mercado se faz necessário. Este trabalho teve por objetivo avaliar o desempenho de genótipos de canola semeados em diferentes épocas no município de Cachoeira do Sul-RS. O trabalho foi conduzido na Fazenda Experimental da UERGS, no município de Cachoeira do Sul-RS. O delineamento experimental adotado foi o de bloco casualizados, em esquema fatorial 5x6, com três repetições. Os fatores foram compostos por cinco diferentes genótipos de canola (Hyola433, Hyola575, Hyola571, Hyola61, Hyola50) e seis épocas de semeadura (21/04; 06/05; 20/05; 10/06; 24/06 e 08/07). Foi estimada a massa de mil grãos (MMG) e a produtividade de cada genótipo para as datas de semeadura estudadas. Os dados foram submetidos à análise de variância, ocorrendo interação significativa, procederam-se os desdobramentos necessários. As médias foram comparadas pelo teste Scott-Knott $(\mathrm{p}<0,05)$. Empregou-se análise de regressão linear para avaliar o efeito do atraso na época de semeadura sobre a produtividade da canola. A massa de mil grãos foi influenciada pela época de semeadura, genótipo e pela interação entre estes fatores. A maior massa de mil grãos $(3,51 \mathrm{~g})$, considerando a média obtida para todos os genótipos, foi observada para semeadura realizada em 21/04. O genótipo Hyola61 apresentou maior massa de mil grãos $(3,47 \mathrm{~g})$, considerando a média obtida para todas as datas de semeadura. A produtividade da cultura da canola foi influenciada pela época de semeadura, genótipo e pela interação entre estes fatores. A semeadura da canola, realizada após 20/05, reduziu a produtividade da cultura, independente do genótipo cultivado.

Palavras-chave: Brassica napus L. var. oleífera. Época de semeadura. Genótipos. Peso de mil grãos. Produtividade.

\section{YIELD PERFORMANCE OF CANOLA GENOTYPES IN THE CENTRAL REGION OF RIO GRANDE DO SUL, BRAZIL}


ABSTRACT: Canola presents as a potential crop for agricultural exploitation in Brazil, and can be inserted in a crop rotation system, however, the identification of sowing seasons and the productive potential of the available genotypes in the market is necessary. The objective of this work was to evaluate the performance of canola genotypes sown at different times in the Cachoeira do Sul city, Rio Grande do Sul state, Brazil. The work was conducted at the Experimental Farm location in Cachoeira do Sul city. The experimental design was randomized block design, in a $5 \times 6$ factorial scheme, with three replications. The factors were composed of five different genotypes of canola (Hyola433, Hyola575, Hyola571, Hyola61, Hyola50) and six sowing seasons (21/04, 06/05, 20/05, 10/06, 24/06 and 08/07). The mass of one thousand grains (MMG) and the yield of each genotype were estimated for the sowing seasons studied. Data were submitted to analysis of variance, with significant interaction occurring, the necessary unfolding proceeded. The means were compared by the Scott-Knott test $(\mathrm{p}<0.05)$. Linear regression analysis was used to evaluate the effect of delay in sowing seasons on canola yield. The mass of a thousand grains was influenced by the sowing season, genotype and by the interaction between these factors. The largest mass of one thousand grains $(3.51 \mathrm{~g})$, considering the average obtained for all genotypes, was observed for sowing on 04/21. The genotype Hyola61 presented the highest mass of one thousand grains (3.47 g), considering the average obtained for all sowing dates. The productivity of the canola crop was influenced by the sowing season, genotype and the interaction between these factors. Sowing of canola, performed after $5 / 20$, reduced the yield of the crop, regardless of the cultivated genotype.

Key words: Brassica napus L. var. oleífera. Sowing time. Genotypes. Weight of one thousand grains. Yield.

\section{INTRODUÇÃO}

A canola é uma espécie que pode ser utilizada para a produção de óleo e na alimentação animal. Em média o farelo de canola apresenta $1.700 \mathrm{kcal}$ de energia metabolizável $/ \mathrm{kg}$, $37,58 \%$ de proteína bruta, $10,45 \%$ de fibra bruta, $0,56 \%$ de cálcio, $0,27 \%$ de fósforo disponível, 2,03\% de lisina, 0,79\% de metionina e 1,64\% de metionina+cistina (ROSTAGNO et al., 2011). Em anos com invernos mais rigorosos, seu cultivo tende a ser mais vantajoso e atraente em relação aos demais, uma vez que a planta apresenta uma maior tolerância às geadas.

A rotação de cultivos com espécies de famílias distintas contribui para a redução de doenças no milho, no trigo e outros cultivos, diminuindo custos associados ao controle fitossanitário e aumentando a eficiência do sistema plantio direto, atendendo assim às atuais necessidades de uma agricultura sustentável (TOMM et al., 2009; EMBRAPA, 2015). Neste cenário, a canola destaca-se como importante espécie alternativa produtora de grãos no período de estação fria do ano nas condições do sul do Brasil (KRÜGER et al., 2011).

Embora a cultura apresente os benefícios anteriormente citados, no Brasil, sua área cultivada ainda é inexpressiva. Segundo Tomm (2007), existem dificuldades tecnológicas para a expansão do cultivo dessa oleaginosa no país, citando como entraves: i) necessidade de 
identificar épocas de semeadura e ii) o ajuste de tecnologias de manejo principalmente em relação à colheita. Outros fatores que impedem a canola de obter no Brasil a mesma expressão quando comparada aos Estados Unidos, Canadá e União Europeia, são as dificuldades mercadológicas e tecnológicas (EMBRAPA, 2009).

A época ideal de semeadura é composta por um conjunto de fatores ambientais que exercem influencia tanto na produtividade quanto na arquitetura e desenvolvimento da planta. A necessidade da espécie a ser semeada e a disponibilidade de recursos do ambiente são fatores que devem ser considerados ao optar por uma determinada época de semeadura. Neste sentido, os possíveis riscos associados às culturas são quantificados, reduzindo os riscos de queda na produtividade (TOMM et al., 2009). A escolha por uma determinada época de semeadura traz consigo a combinação entre fenologia da cultura e a distribuição dos elementos do clima na região de produção que poderá influenciar a produtividade durante o ciclo da cultura (LUZ, 2011).

Para a canola, cultura recente no cenário agrícola do país, tem-se a necessidade da identificação de manejos que permitam explorar o potencial genético dos híbridos existentes no mercado. Dessa forma, identificar a melhor época de semeadura passa a ser um importante aspecto de manejo na cultura da canola por explorar tanto os recursos ambientais quanto os recursos genéticos dos híbridos (LUZ, 2011). O presente trabalho foi realizado com o objetivo de estudar o desempenho produtivo de híbridos de canola semeados em diferentes épocas no município de Cachoeira do Sul-RS.

\section{MATERIAL E MÉTODOS}

O experimento foi conduzido na área experimental da Universidade Estadual do Rio Grande do Sul, localizada a $29^{\circ} 53^{\prime} 00^{\prime \prime}$ de latitude Sul e a $53^{\circ} 00^{\prime} 00^{\prime}$ ' de longitude Oeste, no distrito de Três Vendas, em Cachoeira do Sul/RS. A altitude média da região é de 125 metros. O clima da região é classificado como Cfa (com verão quente). A precipitação média anual varia de 1600 a $1900 \mathrm{~mm}$, com temperatura média anual de $20^{\circ} \mathrm{C}$ (ALVARES et al., 2013). O solo da área experimental é classificado como ARGISSOLO VERMELHO (EMBRAPA, 2013).

O delineamento experimental adotado foi o de bloco casualizados, em esquema fatorial $5 \times 6$, com três repetições. Os fatores foram compostos por cinco diferentes genótipos de canola (Hyola433, Hyola575, Hyola571, Hyola61, Hyola50) e seis épocas de semeadura (21/04; 06/05; 20/05; 10/06; 24/06 e 08/07).

A parcela experimental foi representada por cinco linhas, com 2,0 m de comprimento cada, espaçadas por $0,34 \mathrm{~m}$. Para abertura das linhas de semeadura foi utilizado um rastelo artesanal com cinco hastes de ferro, espaçadas em $0,17 \mathrm{~m}$. A área útil da parcela foi de 1,53 $\mathrm{m}^{2}(1,02 \times 1,5 \mathrm{~m})$.

A semeadura foi realizada de forma manual. Após a semeadura, realizou-se aplicação de fertilizante em cobertura, sendo a dose aplicada de $400 \mathrm{~kg} \mathrm{ha}^{-1}$ de adubo pré-formulado 07-1109 (NPK). Após a emergência, a população de plantas foi ajustada para densidade de 40 plantas por $\mathrm{m}^{2}$, para isso, foi utilizado um gabarito com marcações a cada $7,35 \mathrm{~cm}$, 
representativas do espaçamento entre plantas na linha de semeadura. Quando a cultura atingiu o estádio inicial de florescimento, foi realizada adubação nitrogenada de cobertura, aplicandose $180 \mathrm{~kg}$ de ureia (45\% de N), totalizando um fornecimento de 103,5 kg de nitrogênio por hectare.

O desempenho produtivo dos genótipos de canola, em função da época de semeadura, foi caracterizado computando-se a massa de mil grãos (MMG) e a produtividade. A MMG foi obtido considerando a média do peso de quatro amostras contendo mil grãos, de cada genótipo para cada época de semeadura. A produtividade foi obtida pesando-se a massa de grãos colhidos na área útil da parcela, descontando-se a umidade dos grãos e posteriormente extrapolando-se os valores obtidos para $10.000 \mathrm{~m}^{2}$ (1 hectare).

Os dados foram submetidos à análise de variância, ocorrendo interação significativa, procederam-se os desdobramentos necessários. As médias foram comparadas pelo teste ScottKnott $(\mathrm{p}<0,05)$. Empregou-se análise de regressão linear para avaliar o efeito do atraso na época de semeadura sobre a produtividade da canola. As análises estatísticas foram realizadas no programa computacional SISVAR, versão 5.6 (FERREIRA, 2011).

\section{RESULTADOS E DISCUSSÃO}

Na Figura 1 é apresentada a distribuição pluviométrica, a variação de temperatura durante a condução do experimento e as datas de semeadura da cultura da canola.

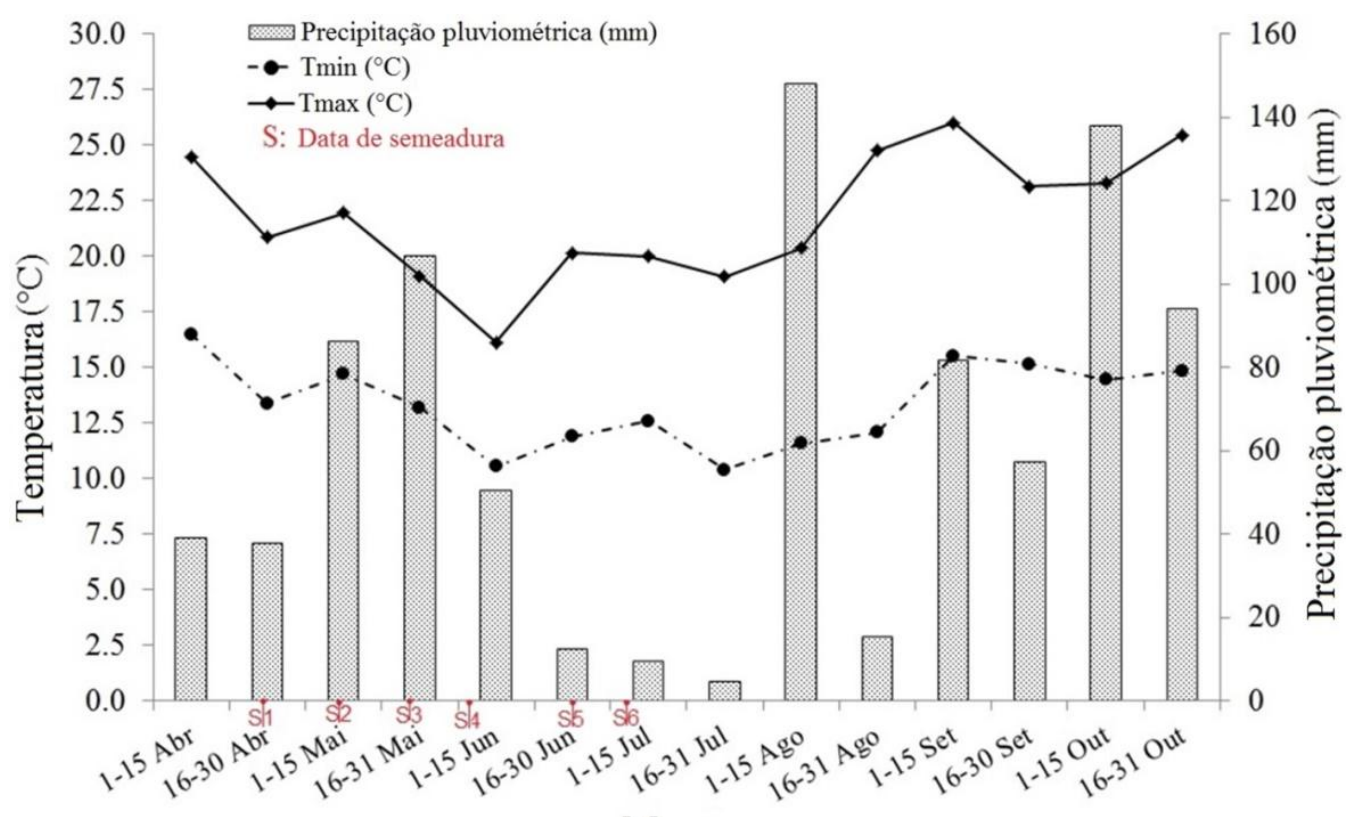

Meses

Figura 1. Distribuição pluviométrica, variação de temperatura e épocas de semeadura dos genótipos de canola (S1: 21/04; S2: 06/05; S3: 20/05; S4: 10/06; S5: 24/06 e S6: 08/07). Rainfall distribution, temperature variation and sowing times of canola genotypes (S1: 21/04; S2: 06/05; S3: 20/05; S4: 10/06; S5: 24/06 e S6: 08/07).

Fonte: Instituto Riograndense do Arroz - IRGA (2017). Riograndense Rice Institute - IRGA (2017). 
A menor precipitação pluviométrica foi observada para o período de 16/06 a 31/07/2017. A falta de água afetou o estabelecimento do estande de plantas da cultura da canola semeada em 24/06 (S5) e 08/07 (S6).

A massa de mil grãos (MMG, g) foi influenciado pelos fatores de variação época e genótipo de forma isolada bem como pela interação entre eles (Tabela 1). Neste caso, foi realizado o desdobramento.

Tabela 1. Análise de variância para massa de mil grãos (MMG, g) em função da época de semeadura, genótipo e interação entre época de semeadura e genótipo. Analysis of variance for one thousand grain mass $(M M G, g)$ as a function of sowing date, genotype and interaction between sowing date and genotype.

\begin{tabular}{lccccc}
\hline \multicolumn{1}{c}{ FV } & Gl & SQ & QM & F & p-valor \\
\hline Época (F1) & 5 & 3,176 & 0,635 & 127,632 & 0,0001 \\
Genótipo (F2) & 4 & 1,564 & 0,391 & 78,587 & 0,0001 \\
F1 x F2 & 20 & 3,166 & 0,158 & 31,810 & 0,0001 \\
erro & 60 & 0,299 & 0,005 & & \\
Total & 89 & 8,205 & & & \\
\hdashline CV $(\%)$ & 2,15 & & & \\
Média geral & 3,278 & Número de observações & 90 & \\
\hline
\end{tabular}

FV: Fatores de variação. gl: graus de liberdade. SQ: Soma de quadrados. QM: Quadrado médio. F: Valor do teste F. FV: Factors of variation. gl: degrees of freedom. SQ: Sum of squares. QM: Medium square. F: Test value $F$.

Fonte: Autoria própria. Own authorship.

Na Tabela 2 é apresentado o resultado para o teste de médias da MMG em função da época de semeadura, genótipo e interação entre época e genótipo.

Tabela 2. Teste de médias para massa de mil grãos (MMG, g) em função da época de semeadura, genótipo e interação entre época de semeadura e genótipo. Test of means for mass of one thousand grains $(M M G, g)$ as a function of sowing date, genotype and interaction between sowing date and genotype.

\begin{tabular}{ccccccc}
\hline \multirow{2}{*}{ Épocas } & \multicolumn{5}{c}{ Genótipos } & \multirow{2}{*}{ Médias } \\
\cline { 2 - 6 } & Hyola433 & Hyola50 & Hyola571 & Hyola575 & Hyola61 & \\
\hline $21 / 04$ & $3,77 \mathrm{aA}$ & $3,24 \mathrm{cA}$ & $3,40 \mathrm{bA}$ & $3,83 \mathrm{aA}$ & $3,31 \mathrm{cC}$ & $3,51 \mathrm{~A}$ \\
$06 / 05$ & $2,87 \mathrm{cD}$ & $3,04 \mathrm{bB}$ & $3,36 \mathrm{aA}$ & $3,05 \mathrm{bE}$ & $3,10 \mathrm{bD}$ & $3,08 \mathrm{C}$ \\
$20 / 05$ & $2,94 \mathrm{bD}$ & $2,98 \mathrm{bB}$ & $2,94 \mathrm{bB}$ & $2,76 \mathrm{cF}$ & $3,23 \mathrm{aC}$ & $2,97 \mathrm{D}$ \\
$10 / 06$ & $3,21 \mathrm{bC}$ & $3,25 \mathrm{bA}$ & $3,31 \mathrm{bA}$ & $3,21 \mathrm{bD}$ & $3,89 \mathrm{aA}$ & $3,38 \mathrm{~B}$ \\
$24 / 06$ & $3,36 \mathrm{cB}$ & $2,83 \mathrm{dC}$ & $3,32 \mathrm{cA}$ & $3,61 \mathrm{bB}$ & $3,81 \mathrm{aA}$ & $3,39 \mathrm{~B}$ \\
$08 / 07$ & $3,45 \mathrm{aB}$ & $3,03 \mathrm{cB}$ & $3,26 \mathrm{bA}$ & $3,49 \mathrm{aC}$ & $3,50 \mathrm{aB}$ & $3,35 \mathrm{~B}$ \\
\hline Médias & $3,27 \mathrm{c}$ & $3,06 \mathrm{~d}$ & $3,15 \mathrm{c}$ & $3,32 \mathrm{~b}$ & $3,47 \mathrm{a}$ & \\
\hline
\end{tabular}

Médias seguidas pela mesma letra, minúscula na linha e maiúscula na coluna, não diferem entre si pelo teste de Scott-Knott $(\mathrm{p}<0,05)$. Means followed by the same letter, lowercase in the line and uppercase in the column, do not differ from each other by the Scott-Knott test ( $p<0.05)$.

Fonte: Autoria própria. Own authorship.

Considerando as médias do PMG, em função da data de semeadura, independente do genótipo, o maior valor obtido foi de 3,51 g, para semeadura realizada dia 21/04. Quando a 
comparação foi feita entre as médias observadas para os genótipos, independente da data de semeadura, a maior massa obtida para mil grãos foi de 3,47 g, para o genótipo Hyola61. Estes valores estão próximos ao encontrado por Krüger et al. (2011), que observou em seu estudo a massa média de mil grãos equivalente a 3,56 g, para semeadura com linhas espaçadas em 0,4 m. Tomm et al. (2008) observaram, para os genótipos Hyola433 e Hyola61, massa de mil grãos equivalente a 3,26 e 3,49 g, respectivamente, em experimento conduzido no Nordeste da Paraíba. Estes valores são semelhantes aos valores médios encontrados neste estudo, 3,27 e 3,47 gramas.

A produtividade da canola também foi influenciada pela época de semeadura, pelo genótipo e pela interação entre eles, conforme análise de variância apresentada na Tabela 3. Neste caso, foi realizado o desdobramento.

Tabela 3. Análise de variância para produtividade de canola $\left(\mathrm{kg} \mathrm{ha}^{-1}\right)$ em função da época de semeadura, genótipo e interação entre época de semeadura e genótipo. Variance analysis for canola yield $\left(\mathrm{kg} \mathrm{ha}^{-1}\right)$ as a function of sowing date, genotype and interaction between sowing date and genotype.

\begin{tabular}{lccccc}
\hline \multicolumn{1}{c}{ FV } & gl & SQ & QM & F & p-valor \\
\hline Época (F1) & 5 & 18935084,556 & 3787016,911 & 53,097 & 0,0001 \\
Genótipo (F2) & 4 & 788465,426 & 197116,357 & 2,764 & 0,0355 \\
F1 x F2 & 20 & 7063648,798 & 353182,439 & 4,952 & 0,0001 \\
Erro & 60 & 4279370,113 & 71322,835 & & \\
Total & 89 & 31066568,893 & & & \\
\hdashline
\end{tabular}

CV $(\%) \quad 16,30$

Média geral 1638,0499 Número de observações 90

FV: Fatores de variação. gl: graus de liberdade. SQ: Soma de quadrados. QM: Quadrado médio. F: Valor do teste F / FV: Factors of variation. gl: degrees of freedom. SQ: Sum of squares. QM: Medium square. F: Test value $F$.

Fonte: Autoria própria. Own authorship.

$\mathrm{Na}$ Tabela 4 é apresentado o resultado para o teste de médias da produtividade da canola em função da época de semeadura, genótipo e interação entre época e genótipo. Considerando a produtividade média entre todos os híbridos, as maiores produtividades foram obtidas para as três primeiras épocas de semeadura. Considerando a produtividade média para todas as épocas de semeadura, os híbridos Hyola433 e Hyola61 apresentaram os maiores valores.

Foi observado que a produtividade da canola, considerando a média dos cinco híbridos estudados, sofreu uma drástica redução para semeaduras realizadas após 20 de maio de 2017. Se contabilizado a média de produtividade para as três primeiras datas e para as três últimas, a perda observada é de $849,237 \mathrm{~kg} \mathrm{ha}^{-1}$, a qual representa uma redução de, aproximadamente, 14 sacas, ou $41,17 \%$.

Uma das causas desta queda de produtividade pode estar associada aos picos de temperatura observados durante a fase de floração da cultura da canola, que, para as duas últimas datas de semeadura, ocorreu após a segunda quinzena de agosto. Tomm et al. (2008) em ensaios realizados no Nordeste do estado da Paraíba, observaram que o aumento da 
temperatura média $\left(21,2\right.$ para $\left.23,7^{\circ} \mathrm{C}\right)$ ocasionou maior abortamento de flores terminais e desuniformidade no enchimento de síliqua.

Tabela 4. Teste de médias para a produtividade de canola $\left(\mathrm{kg} \mathrm{ha}^{-1}\right)$ em função da época de semeadura, genótipo e interação entre época de semeadura e genótipos. Mean test for canola yield $\left(\mathrm{kg} \mathrm{ha}^{-1}\right)$ as a function of sowing date, genotype and interaction between sowing date and genotypes.

\begin{tabular}{ccccccc}
\hline \multirow{2}{*}{ Épocas } & \multicolumn{5}{c}{ Genótipos } & \multirow{2}{*}{ Médias } \\
\cline { 2 - 6 } & Hyola433 & Hyola50 & Hyola571 & Hyola575 & Hyola61 & \\
\hline $21 / 04$ & $2371,36 \mathrm{bA}$ & $2309,86 \mathrm{bA}$ & $1441,41 \mathrm{cB}$ & $1689,44 \mathrm{cB}$ & $2726,14 \mathrm{aA}$ & $2107,65 \mathrm{~B}$ \\
$06 / 05$ & $1705,75 \mathrm{bB}$ & $1496,06 \mathrm{bB}$ & $1993,72 \mathrm{aA}$ & $1538,40 \mathrm{bB}$ & $2137,10 \mathrm{aB}$ & $1774,21 \mathrm{C}$ \\
$20 / 05$ & $2385,73 \mathrm{bA}$ & $2169,58 \mathrm{bA}$ & $2088,06 \mathrm{bA}$ & $2080,38 \mathrm{bA}$ & $2807,03 \mathrm{aA}$ & $2306,15 \mathrm{~A}$ \\
$10 / 06$ & $1624,10 \mathrm{aB}$ & $1402,96 \mathrm{aB}$ & $1310,07 \mathrm{aB}$ & $1191,75 \mathrm{aC}$ & $1041,50 \mathrm{aC}$ & $1314,07 \mathrm{D}$ \\
$24 / 06$ & $1057,12 \mathrm{aC}$ & $1300,73 \mathrm{aB}$ & $1251,83 \mathrm{aB}$ & $965,11 \mathrm{aC}$ & $730,58 \mathrm{aC}$ & $1061,08 \mathrm{E}$ \\
$08 / 07$ & $1413,43 \mathrm{aB}$ & $924,74 \mathrm{bC}$ & $1527,53 \mathrm{aB}$ & $1545,41 \mathrm{aB}$ & $914,62 \mathrm{bC}$ & $1265,14 \mathrm{D}$ \\
\hline Médias & $1759,59 \mathrm{a}$ & $1600,65 \mathrm{~b}$ & $1602,10 \mathrm{~b}$ & $1501,75 \mathrm{~b}$ & $1726,16 \mathrm{a}$ & \\
\hline
\end{tabular}

Médias seguidas pela mesma letra, minúscula na linha e maiúscula na coluna, não diferem entre si pelo teste de Scott-Knott $(\mathrm{p}<0,05)$. Means followed by the same letter, lowercase in the line and uppercase in the column, do not differ from each other by the Scott-Knott test ( $p<0.05)$.

Fonte: Autoria própria. Own authorship.

Temperaturas acima de $27^{\circ} \mathrm{C}$, associadas principalmente ao déficit hídrico, durante o período de floração, podem resultar em redução de até $50 \%$ do rendimento de grãos. Este fato é explicado pela redução no período de floração, o que afeta a viabilidade do polem e a receptividade das flores, além disso, ocorre maior abortamento de síliquas (ANGELOTTIMENDONÇA et al., 2016).

A produtividade média da canola, calculada para todas as épocas de semeadura, apresentou diferença significativa apenas entre os genótipos Hyola433 e Hyola575, com valores de 1759,59 e $1726,16 \mathrm{~kg} \mathrm{ha}^{-1}$. Foi observado que todos os genótipos apresentaram produtividade acima da média nacional, que é estimada em $1550 \mathrm{~kg} \mathrm{ha}^{-1}$ (CONAB, 2017), para ao menos uma data de semeadura. Isso demonstra que a introdução da cultura da canola em um sistema de rotação de culturas é promissora.

Todos os genótipos estudados apresentaram produtividade média acima de $2.000 \mathrm{~kg} \mathrm{ha}^{-1}$ quando semeados em 20/05, ou seja, na terceira época estudada. Este fato pode estar associado às condições climáticas favoráveis necessárias para o estabelecimento inicial da cultura. A produtividade obtida por Tomm et al. (2008), para os genótipos Hyola433 e Hyola61 foi de 2196 e $1811 \mathrm{~kg} \mathrm{ha}^{-1}$, respectivamente. No presente estudo, produtividade superior foi obtida para semeadura realizada em 21/04 e 20/05, para o genótipo Hyola433. Para o genótipo Hyola61, produtividade superior foi observada para semeadura realizada em 21/04, 06/05 e 20/05, demostrando que este genótipo permite um atraso maior na época de semeadura. 
Considerando a produtividade média de canola em cada data de semeadura, foi observada diferença estatística significativa. Na Figura 3 é apresentado o gráfico e a equação de ajuste da análise de regressão linear para produtividade da cultura da canola (Y) em função das épocas de semeadura (x).

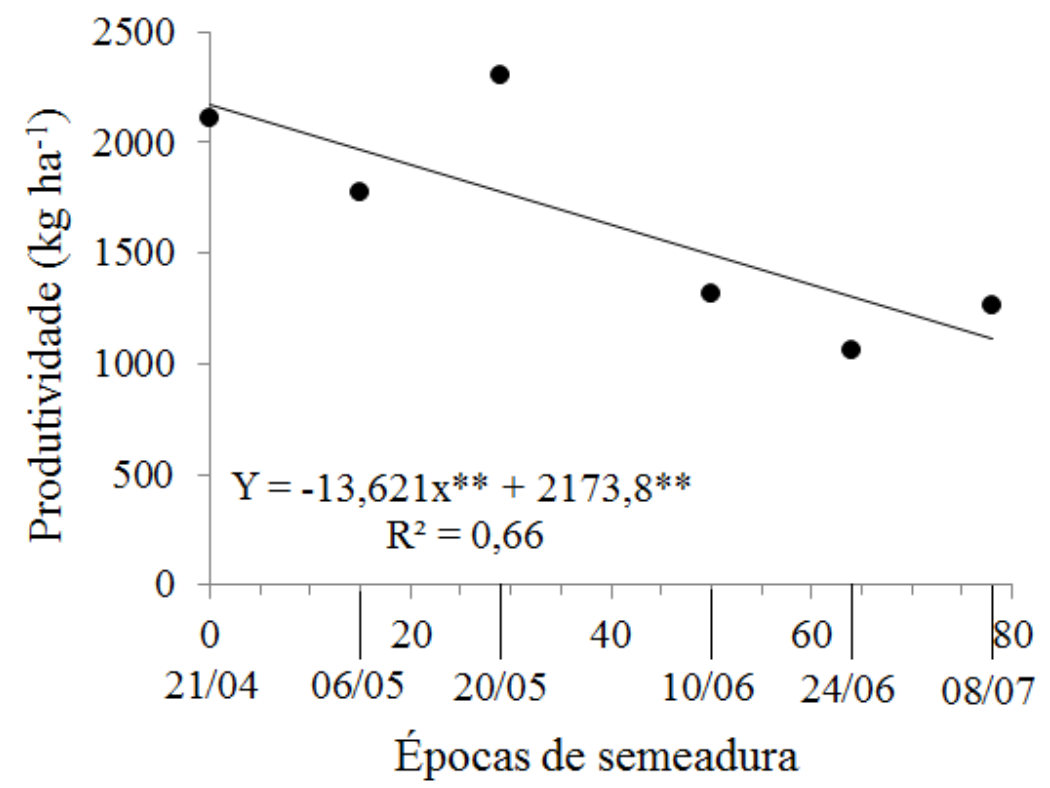

Figura 3. Gráfico de regressão e equação de ajuste do modelo linear para análise de regressão da produtividade $(\mathrm{Y})$ em função das épocas de semeadura $(\mathrm{x})$. **coeficientes significativos (p-valor $<0,01)$. Regression graph and fit equation of the linear model for yield regression analysis $(Y)$ as a function of sowing dates $(x)$. ** significant coefficients (p-value <0.01).

Fonte: Autoria própria. Own authorship.

Pode-se observar que, de acordo com o modelo ajustado, o atraso na semeadura pode resultar em perda de produtividade na ordem de 13,621 $\mathrm{kg} \mathrm{ha}^{-1}$ para cada dia de atraso na semeadura, a contar para semeadura realizada em 21/04. Krüger et al. (2011) comprovaram em seu estudo que os efeitos proporcionados pelo ano de cultivo são mais efetivos em alterar a produção de grãos em canola, seguido do potencial genético da cultivar e com menor participação da densidade de cultivo. Neste contexto, considerando a canola uma cultura estratégica em um sistema de rotação de culturas, considerando também a expectativa do produtor rural em obter lucro com seu cultivo, trabalhos como o presente são de extrema relevância, em especial, para culturas que apresentam pouco estudo e necessitam de ajustes tecnológicos para expandir suas áreas de cultivo. Além disso, a escolha do híbrido de maior desempenho também é chave. Contudo, haja vista que os anos agrícolas não apresentam o mesmo comportamento climático, se faz necessário repetir este tipo de estudo para que a assertividade na recomendação da data de semeadura e do híbrido a ser cultivado seja garantida.

\section{CONCLUSÃO}

A massa de mil grãos foi influenciada pela época de semeadura, genótipo e pela interação entre estes fatores. 
A maior massa de mil grãos $(3,51 \mathrm{~g})$, considerando a média obtida para todos os genótipos, foi observada para semeadura realizada em 21/04.

O genótipo Hyola61 apresentou maior massa de mil grãos $(3,47 \mathrm{~g})$, considerando a média obtida para todas as datas de semeadura.

A produtividade da cultura da canola foi influenciada pela época de semeadura, genótipo e pela interação entre estes fatores.

A semeadura da canola, realizada após 20/05, reduziu a produtividade da cultura, independente do genótipo cultivado.

\section{AGRADECIMENTOS}

Os autores agradecem a EMBRAPA Trigo, em especial ao Pesquisador Dr. Gilberto Omar Tomm, pela disponibilização dos genótipos, á Universidade Federal de Santa Maria (UFSM) pela concessão de bolsa de estudo e á Universidade Estadual do Rio Grande do Sul (UERGS) pela disponibilização da área experimental.

\section{REFERÊNCIAS BIBLIOGRÁFICAS}

ALVARES, C. A.; STAPE, J. L.; SENTElHAS, P. C.; GONÇALVES, J. L. M.; SPAROVEK, G. Köppen's climate classification map for Brazil. Meteorologische Zeitschrift, Stuttgart, v. 22, n. 6, p.711-728, 2013.

ANGELOTTI-MENDONÇA, J.; RIBOLDI, L. B.; SOARES, C. D. F.; CAMARGO E CASTRO, P. R.; KLUGE, R. A. Canola (Brassica napus L.). Piracicaba: ESALQ / Divisão de Biblioteca, 2016. 32 p. (Série Produtor Rural, n. 61)

COMPANHIA NACIONAL DE ABASTECIMENTO - CONAB. Acompanhamento da safra brasileira de grãos, v. 4, Safra 2016/17: décimo segundo levantamento. Brasília, DF, 2017. 158 p. Disponível em: http://www.conab.gov.br/OlalaCMS/uploads/arquivos/17_09_12_10_14_36_boletim_graos_s etembro_2017.pdf. Acesso em: 14 dez. 2017.

EMPRESA BRASILEIRA DE PESQUISA AGROPECUÁRIA - EMBRAPA. Sistema Brasileiro de Classificação de Solos. 3. ed. Brasília: Embrapa Informação Tecnológica, 2013. 353 p.

EMPRESA BRASILEIRA DE PESQUISA AGROPECUÁRIA - EMBRAPA. Análise do rendimento de grãos, custo e eficiência do processo produtivo agrícola. Passo Fundo, 2009. Disponível em: http://www.cnpt.embrapa.br/biblio/do/p_do118_9.htm. Acesso em: 14 dez. 2017. (Documentos online, n. 118)

EMPRESA BRASILEIRA DE PESQUISA AGROPECUÁRIA - EMBRAPA. Sistema de produção: 3: cultivo de canola. Passo Fundo: Embrapa Trigo, 2015. Disponível em: https://www.spo.cnptia.embrapa.br/conteudo?p_p_id=conteudoportlet_WAR_sistemasdeprod ucaolf6_1ga1 ceportlet\&p_p_lifecycle=0\&p_p_state=normal\&p_p_mode=view\&p_p_col_id= 
column-2\&p_p_col_count=1\&p_r_p_-76293187_sistemaProducaoId=3703\&p_r_p_996514994_topicoId=3024. Acesso em: 15 out. 2017.

FERREIRA, D. F. Sisvar: a computer statistical analysis system. Ciência e Agrotecnologia Lavras, MG, v. 35, n. 6, p.1039-1042, 2011.

KRÜGER, C. A. M. B.; SIlvA, J. A. G.; MEDEIROS, S. L. P.; DALMAGO, G. A.; SARTORI, C. O.; SCHIAVO, J. Arranjo de plantas na expressão dos componentes da produtividade de grãos de canola. Pesquisa Agropecuária Brasileira, Brasília, v. 46, n. 11, p.1448-1453, 2011.

LUZ, G. L. Exigência térmica e produtividade de canola em diferentes épocas de semeadura em Santa Maria-RS. 2011. 69 f. Tese (Doutorado em Agronomia) Universidade Federa de Santa Maria, Santa Maria, 2011.

ROSTAGNO, H. S.; ALBINO, L. F. T.; DONZELE, J. L.; GOMES, P. C.; OLIVEIRA, R. F.; LOPES, D. C.; FERREIRA, A. S.; BARRETO, S. L. T.; EUCLIDES, R. F. Tabelas brasileiras para aves e suínos: composição de alimentos e exigências nutricionais de aves e suínos. 3. ed. Viçosa: UFV, 2011. 252 p.

TOMM, G. O. Indicativos tecnológicos para produção de canola no Rio Grande do Sul. Passo Fundo: Embrapa Trigo, 2007. 68 p.

TOMM, G. O.; RAPOSO, R. W. C.; SOUZA, T. A. F.; OLIVEIRA, J. T. L.; RAPOSO, E. H. S.; SILVA NETO, C. P.; BRITO, A. C.; NASCIMENTO, R. S.; RAPOSO, A. W. S.; SOUZA, C. F. Desempenho de genótipos de canola (Brassica napus L.) no Nordeste do estado da Paraíba, Nordeste do Brasil. Passo Fundo: Embrapa Trigo, 2008. 15 p. (Boletim de Pesquisa e Desenvolvimento Online, 65). Disponível em: http://www.cnpt.embrapa.br/biblio/bp/p_bp65.htm. Acesso em: 23 out. 2017.

TOMM, G. O.; WIETHOLTER, S.; DALMAGO, G. A.; SANTOS, H. P. Tecnologia para produção de canola no Rio Grande do Sul. Passo Fundo: Embrapa Trigo, 2009. 41 p. Disponível em: http://www.cnpt.embrapa.br/biblio/do/p_do113.htm. Acesso em: 14 dez. 2017. 